\title{
Explaining the Concept of Learning Based on Reflection in Clinical Education: Scoping Review
}

\author{
Soleiman Ahmady ${ }^{1,2}$, Zahra Ayazi ${ }^{3 *}$, Masomeh Kalantarion³, Nasrin Khajeali
}

\author{
'Head of Department of Medical Education, Virtual School of Medical Education and Management, Shahid Beheshti University of Medical Sciences, Tehran, Iran; \\ Research Affiliated Faculty at Department of LIME, Karolinska Institute, Sweden. \\ Department of Medical Education, Virtual School of Medical Education and Management, Shahid Beheshti University of Medical Sciences, Tehran, Iran. \\ 4Department of Medical Education, Jundishapur University of Medical Sciences, Ahvaz, Iran. \\ *Correspondence to: Zahra Ayazi (E-mail: ayazi_z56@yahoo.com) \\ (Submitted: 02 September 2021 - Revised version received: 21 September 2021 - Accepted: 11 October 2021 - Published online: 26 December 2021)
}

\begin{abstract}
Objective: This study was conducted with the aim of theoretically explaining the concept of reflection in medical science education in texts and identifying the dimensions and characteristics of education based on reflection and their application in clinical nursing education and existing models in 2021.

Methods: This scoping review was conducted in five phases following the method developed by Denyer and Tranfield. The scope of the review was limited to Reflection and Reflective in nursing education. Using the keywords in combination and separately, they were searched in databases of ERIC/ www.iranmedex.com/ www.magiran.com/ www.irandoc.ac.ir/ www.sid.ir/ www.medlib.ir/ All Sciences/ Web of Science/Search Engines Google/Google scholar/Scopus/Ovid/ERIC/Wiley/PubMed and Science Direct from1970s to 2021.

Results: Based on inclusion and exclusion criteria, 24 articles and documents were selected. During the theoretical explanation of the concepts and components of reflection in clinical nursing education, the model is abstracted. In this model: The Clinical education triangle has 3 main components in its three angles: patient, teacher, or tutor, and student. It is necessary that the sides of this triangle including teaching-learning, teaching-caring, and caring-learning to be formed in the best way and to serve the student and the patient.

Conclusion: The results of this study emphasize the practical and constructive nature of knowledge in learning based on reflection and its special position so that by eliminating the gap between theory and practice in nursing education, one can see the excellence of the operational part of education and promotion of the level of health of the society by providing an appropriate performance of the nursing staff.

Keywords: Reflection, clinical education, scoping review, nursing, theoretical model
\end{abstract}

\section{Introduction}

"Reflection in the field of learning" is a general term for mental and emotional activities in which people engage to discover their experiences which leads to a new understanding. Learning based on reflection is the process of exploring and discovering the subject matter that has been considered through experience, where the individual generates and clarifies the meaning by himself, and the conceptual view of the individual is modified. Learning based on reflection requires learners to review their previous interpretations of knowledge and, as a group, create a new common sense of position and commitment to action based on this new learning. ${ }^{1}$ Therefore, reflection is addressed with terms like Reflective training, Reflective Teaching, Reflective learners, Reflective skills, or Reflection.

Approaches used to promote learning based on reflection include action research, case write-ups, microteaching, and supervised practicals. ${ }^{2,3}$

Nursing is a professional knowledge that is dependent on practice along with science. In a way that in many studies, it is known as practice-oriented professional. In the field of testing science and nursing, art is in the domain of clinical, so in addition to learning knowledge, a nursing student needs to learn

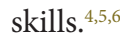

Clinical education is undoubtedly the most important and fundamental part of the nursing education program..${ }^{7,8}$ It is close to half of the undergraduate education and therefore clinical education is referred to as the heart of nursing education. ${ }^{9}$ The value of clinical education is accepted by all; And all experts in the field of nursing education believe that the development of scientific and professional nursing education is impossible without improving clinical education. In this regard, many nursing schools consider the evaluation of clinical education as the main pillar of educational planning. ${ }^{10}$

It is important for "both the nurse and the patient" to perform along with a reflective approach in nursing practices. In holistic caregiving, nurses in the task of taking care of mankind, should always consider mankind with a holistic nature and provide care considering all his dimensions; and in this area, perform their caregiving actions with the least mistakes. Therefore, it is necessary to reflect on the desired action while performing specific measures or to reflect after performing them, so that the distance between theory and practice is reduced and the necessary points are learned from specific experiences. ${ }^{11}$ The importance of a reflective approach for a nurse is because one can avoid making mistakes or substitute the right things. So it can help to increase the development of his abilities; in a way that when performing reflection, nurses become able to provide their care with better understanding and more competent knowledge and have motivation in changing and improving the quality of holistic care. ${ }^{11}$ Since clinical education and the need to reduce and eliminate the gap between theoretical and clinical education in nursing education have a special position, so it seems that the use of models such as reflection, is effective in this regard. Therefore, this study was conducted with the aim of theoretically 
explaining the concept of reflection in medical science education in texts and identifying the dimensions and characteristics of education based on reflection and their application in clinical nursing education and existing models in 2021.

\section{Materials and Methods}

The concept of reflection, despite its relatively broad application, does not have clear definitions and there is some degree of ambiguity and lack of transparency around its characteristics. Therefore, in order to distinguish this concept in medical education from similar concepts and also because of lack of the provision of a specific model of reflection in the clinical education of nursing in the world and Iran, we decided to use the method of "Arksey \& O'Malley Scoping review", ${ }^{12}$ with a general overview, so that while clarifying the concept of reflection and examining the existing models, a comprehensive model of their integration is provided.

Scoping review is used to quickly provide a concept map, main sources, and key evidence of research background and can be used as an independent background review project in cases that are both a broad field of study and are not been comprehensively studied in the past. ${ }^{13}$

The research methodology is defined by Denyer and Tranfield based on five steps of structuring the research, determining the scope of the study, selecting and reviewing articles, data analysis, and conclusions. ${ }^{14}$

In the first step, research questions were determined as: "What are the concepts and components of reflection in medical education, especially clinical education?" Then, in the second step, to answer the questions of the previous step, the following different electronic databases were used systematically:

ERIC/ www.iranmedex.com/ www.magiran.com/ www. irandoc.ac.ir/ www.sid.ir/ www.medlib.ir/ All Sciences/ Web of Science/ Search Engines Google/ Google scholar/ Scopus/ Ovid/ ERIC/ Wiley/ PubMed and Science Direct.

Given that there was no other equivalent for the word Reflection in the Mesh Dictionary, the following keywords were used to search for a wide range of articles:

"Reflection, Reflective Learning, Reflective training, Reflective Teaching, Reflective thinking, Reflective Practice" OR "levels of reflectivity, Reflective Learning model, Reflective Practice in nursing."

The above keywords were searched in English and Farsi during the 1970s (the introduction of the term Reflection and Reflective in education by Burton) till 2021 in the mentioned databases.

In order to select the main studies in the third step: inclusion and exclusion criteria were modified and adjusted based on the research question and scoping review objectives during the searches and study of documents during an interactive process.

Articles that are published in English or Farsi and in a scientific-research journal (approved) and the term Reflection or Performance-based on Reflection is in the title or abstract and their full text is available were included in the study.

Criteria for excluding sources from the study were: lack of access to the full text of the article, scientific-promotional articles, letter to the editor, lecture, critique report, or articles not related to the field of medical education.

In the initial search, several articles were found. In the first stage, after reviewing the titles of the articles (1414 items), a large number of sources were removed due to lack of thematic relevance (1308 items), and 110 articles, books, and documents were selected for further review. Then the summary of the articles was studied and those relevant to the concept of reflection in clinical education particularly nursing were chosen for full text studying. At this stage, 52 articles and documents of which full texts were available were read. Finally, based on inclusion and exclusion criteria, 24 articles and documents which had stated complete details regarding the desired concept, were selected as a base for scoping review and chosen for inclusion in the analysis (Figure 1).

In the fourth step, after the final sources were selected, the definitions and frameworks provided in these sources were reviewed and the details of each of these definitions, frameworks, and models were embedded in the Excel software for better matching and comparison in the next stage. ${ }^{12}$

The purpose of collecting studies in the fifth step was to compile and summarize the results and provide a report. Analysis and combining of results is part of any review study, but the depth and type of analysis in this method was different from the systematic review because, in this type of study, the results of a scoping study are usually displayed in tabular form with some narrative interpretations by the researcher ${ }^{15}$ wherein this study, by matching different findings in relevant researches and relevant, a summary is given in Tables 1 and 2 .

\section{Ethical Considerations}

The data were collected after obtaining the approval of the research proposal from the Ethics Committee of the Shahid Beheshti University of Medical Sciences (IR.SBMU.SME. REC.1400.014).

\section{Results}

Definitions and various components of reflection in the researched models and the consequences obtained in the models are summarized (Table 1); then the articles related to the relevant topics in the world are presented (Table 2); therefore, ultimately we are able to present a conceptual model of

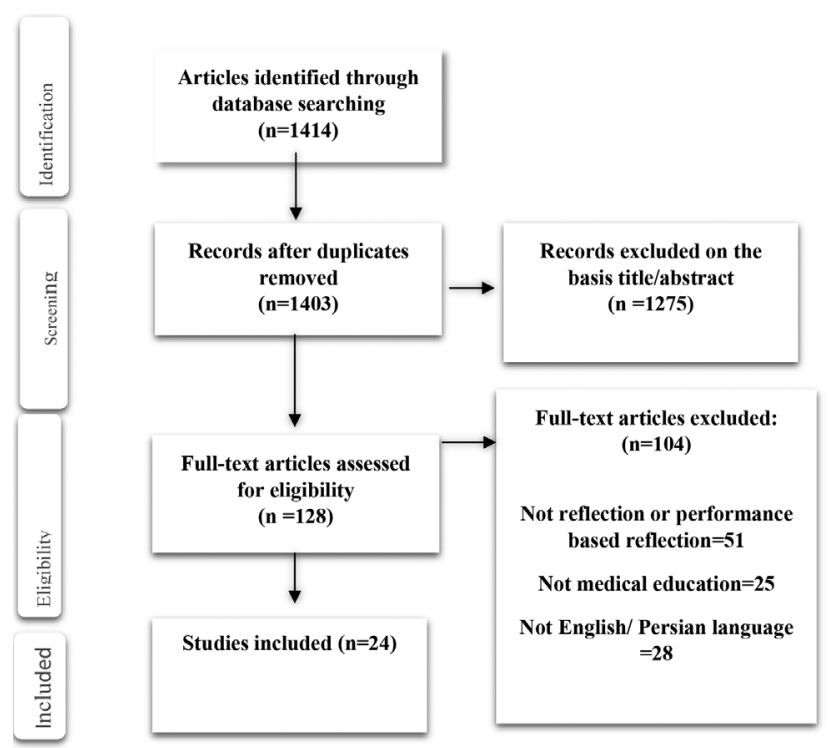

Fig. 1 Selection process of studies to include in the scoping review. 


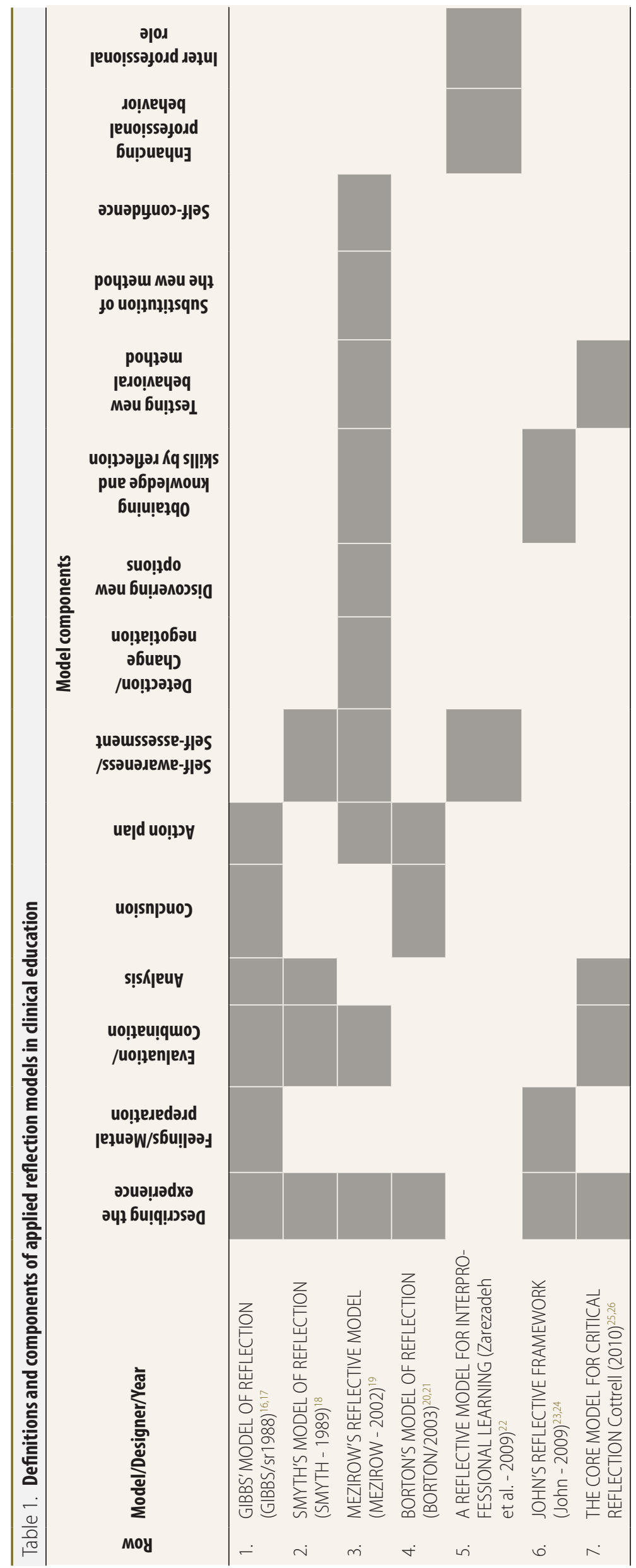




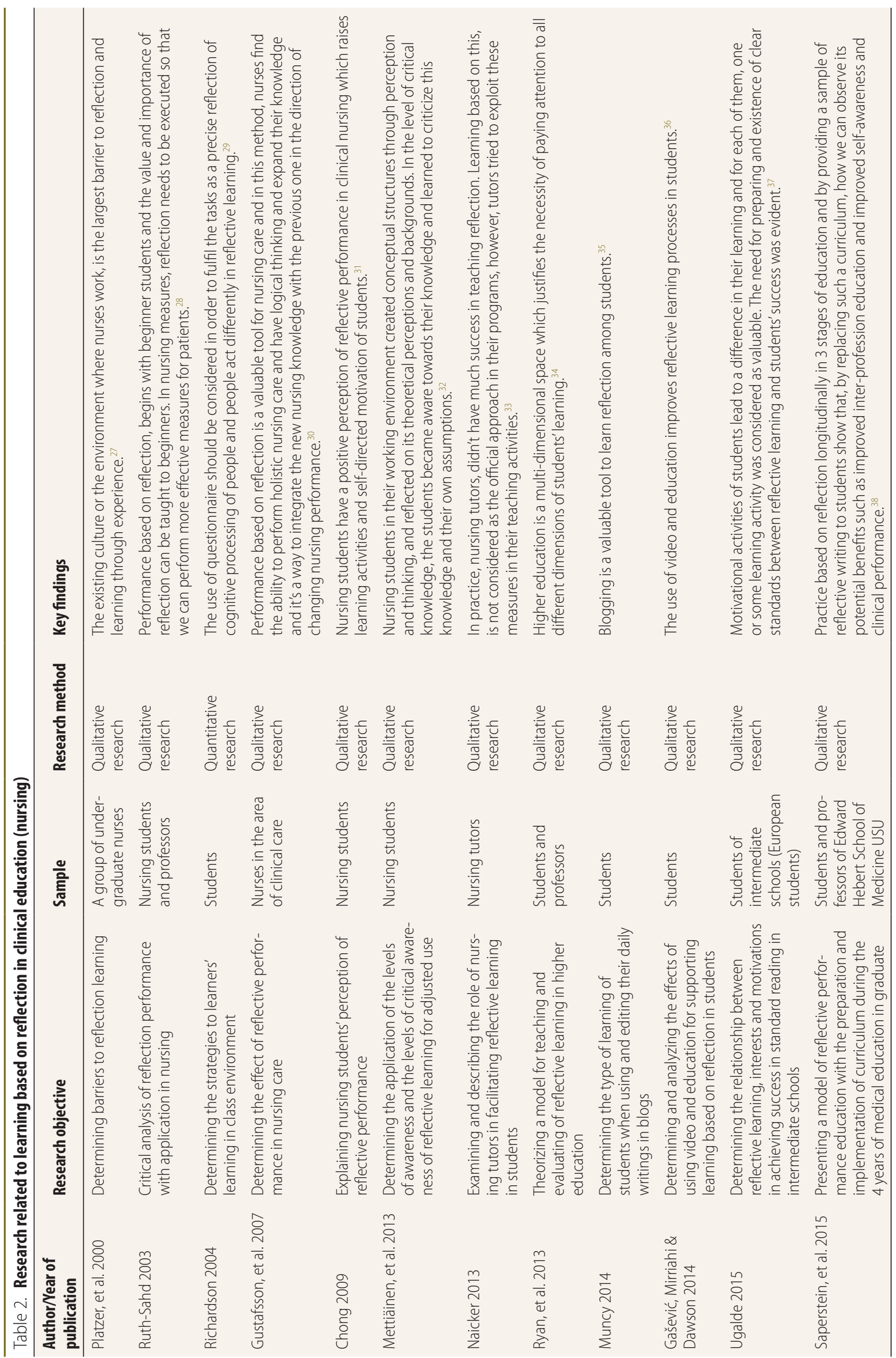




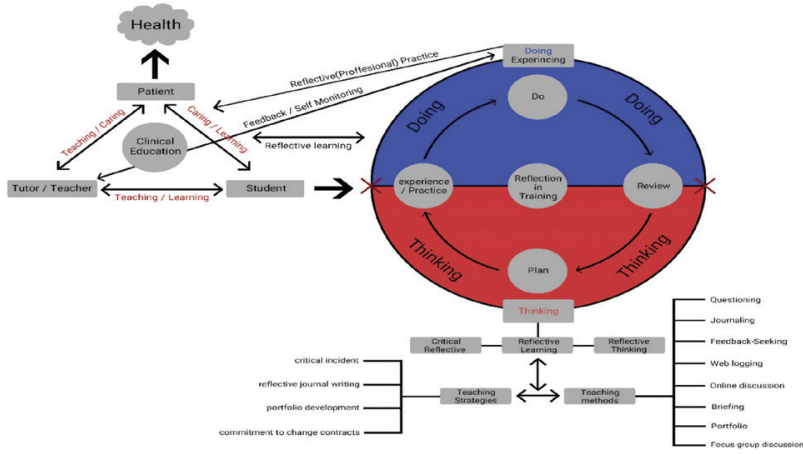

Fig. 2 Conceptual model of reflection and learning based on it.

reflection and learning based on it from the scoping review (Figure 2) with the use of the potential of this kind of learning for further application in clinical education specifically for nurses for the study objectives.

\section{Conceptual Model of Reflection and Learning Based on it from Scoping Review}

During the theoretical explanation of the concepts and components of reflection in medical education in the text and identifying the dimensions and characteristics of education based on reflection and their application in clinical nursing education, the model is schematically abstracted (Figure 2).

In this model: the clinical education triangle has 3 main components in its three angles: patient, teacher, or tutor, and student. The purpose of these components in the clinic is to achieve patient health. In this way, it is necessary that the sides of this triangle including teaching-learning, teaching-caring, and caring-learning to be formed in the best way and to serve the student and the patient.

In order for the student to learn better, in the clinic, benefiting from his experience, the teacher and patient enter a cycle that focuses on reflection in education and has 4 cyclic stages of Do/Review/plan/experience or practice. In the case of implementing these stages, the student enters the phase of thinking which, by thinking about experiences, manifests as Reflective thinking, Critical Reflective, or Reflective Learning. Teachers use different teaching methods and teaching strategies to teach better. In case of implementing the stages of Review/Do/Experience or practice, the student enters the phase of Doing/Experiencing and tries to take proper clinical measures for the patient by achieving Reflective (professional) practice and it's in this stage that along with self-monitoring, the teacher also gives feedback. The key point of this model is that a clinical student, including nursing, after the theory training process and reaching this point of clinical training, still has a gap between theory and practice, which with the help of professors, this gap must be repaired and compensated based on reflection so that a nursing student can better provide clinical services and bring the health system and patient closer to the lofty goal of recovery and promotion of health.

\section{Discussion}

As Freshwater addressed it in 2002, "being a good therapeutic staff and physician" requires appropriate knowledge and skills, but it also requires establishing and maintaining a therapeutic relationship between patients and their caregivers. ${ }^{39}$
This concept implies that a good relationship with the patient has a beneficial effect on the well-being and improvement of the patient. The importance of a therapeutic relationship has long been recognized in psychotherapy, but recent attention to patient-centered care suggests improvements in outcomes such as patient satisfaction and improved chronic patient care. ${ }^{40}$

An essential aspect of relationship therapy is recognizing and understanding the personal beliefs and value systems of the people involved, both physicians and patients. There may be differences between these systems and this can cause an acute emotional reaction in the physician which in turn may affect his next decisions and measures. Recent neurological research shows that effective reasoning is a largely unconscious process in which there is a modulation of the logical processing of information by emotions. For example, anger towards a patient may lead to a response that would be different if it was empathy. Establishing a therapeutic relationship is an essential component of professional practice and a key characteristic of professionalism. Reflection directed by a supervisor or advisor is very beneficial for this approach because the beliefs and main and essential presumptions of the individual are identified and challenged. Reflection is important for establishing a therapeutic relationship, especially for postgraduate education and continuing medical education, but it is also used for general medical education, especially during the clinical period. ${ }^{40}$

Reflection is effective in developing professional practice. Therapeutic staff and physicians often have to respond to a wide range of conditions that are both complex and not well defined. This "disorder" of professional practice is at the heart of professional expertise. ${ }^{41}$

Experts are quick to make decisions that are appropriate to these complex situations, and they are able to create a set of mental models through an action-on-reflection process that mobilizes them quickly and can effectively resolve the situation through action-in-reflection. Developing professional expertise requires nothing more than a set of knowledge and skills. $^{42}$

The performance of an expert is a complex combination of knowledge and skills tailored to the unique situation he or she faces. Frequent confrontation with the complexities of professional life is an essential issue and directed reflection can maximize the opportunity to learn in this approach. Reflection is essential in developing professional acts for postgraduate education and continuous education. Although these three approaches have different outcomes, they all have an essential aspect. A conscious process to develop perception and create meaning from one situation to future measures done consciously is the essence of reflection.

In this study, only one study compared different methods. This study was conducted to identify whether writing an important incident report, two-person interview, or a combination of the two, is more effective in creating a reflection. The results of this study indicate that interview with a tutor is the most effective way to reflect on professionalism. During the experience of medical school, there is no longitudinal study and evidence of the benefits of reflection in long-term development, especially in subsequent clinical care. However, reflection in general medicine students has increased selfreport measures about self-awareness, professional thinking skills, and skills needed for close examination of patients. ${ }^{43}$ 
Four studies that reported positively targeted results in reflection were: Increased skill in reflection and diagnostic thinking (Sobral, 2000), professional identity (Niemi, 1997), medical-humanistic skills score (Wiecha et al. 2002), and final examination results for obstetrics (Lonka et al., 2001). As a result, students found that reflection was helpful, and the application of reflection led to improved self-report outcomes and objective learning and professional development. ${ }^{44-47}$ Grant et al. in 2006, by a study of first-year medical students, showed that instead of text-based reflection writing methods, students prefer to pursue group-based and creative reflective activities. ${ }^{48}$ It seems that the experience of the use of multimedia, voice, image, and video and creatively exploiting them for reflection, like digital storytelling, not only increases the students' involvement but also increases the depth of their reflection. ${ }^{49}$ Individuals have a variety of preferred methods for presenting their thoughts and feelings, including painting, photography, and sculpture. ${ }^{50}$

\section{Conclusion}

What emerges from the study of relevant research in the field of reflective learning indicates that the idea of this model entered the field of learning and education from Burton in 1970 and gradually became more apparent in clinical education. Of course, clinical education of students needs a lot of effort so that by reflection, one can expect the better performance of the students, especially the big group of nursing students. The results of reviewing various researches in parallel have confirmed the efficiency and positive effect of this type of learning in acquiring skills, student motivation, and the ability of collaborative learning and subsequently improving skills in clinical and working environments. But in order to separate from the traditional texture of education and learning, much effort is required in the implementation of this method and the result of combining the data of studied researches also emphasizes the practical and constructive nature of knowledge in learning based on reflection and its special position so that by eliminating the gap between theory and practice in clinical education, one can see the excellence of the operational part of education and promotion of the level of health of the society by providing an appropriate performance of the nursing staff.

\section{Acknowledgments}

This study is the result of a $\mathrm{PhD}$ thesis at Shahid Beheshti University of Medical Sciences by the second author.

\section{Conflicts of Interest Disclosure}

The authors declare no conflicts of interest.

\section{References}

1. Vachon B, LeBlanc J. Effectiveness of past and current critical incident analysis on reflective learning and practice change. Medical education. 2011;45(9):894-904.

2. Mubuuke AG, Kiguli-Malwadde E, Kiguli S, Businge F. A student portfolio: the golden key to reflective, experiential, and evidence-based learning. Journal of medical imaging and radiation sciences. 2010:41(2):72-8.

3. Yasin RM, Rahman S, Ahmad AR. Framework for reflective learning using portfolios in pre-service teacher training. Procedia-Social and Behavioral Sciences. 2012;46:3837-41.

4. Elena S. Reflective capability-a specific goal of a Teachers Professional Ethics Course. Procedia-Social and Behavioral Sciences. 2011:11:145-9.

5. Park JY, Son J-B. Expression and connection: the integration of the reflective learning process and the writing process into social network sites. Journal of Online Learning and Teaching. 2011;7(1):170-8.

6. Pollard C, Stringer E, Cockayne D. Clinical Clinical education: A review of the literature nurse education in practice.Nurse EducPract.2007;7(5):315-22.

7. Nahas VL, Nour V, Al- Nobani M. Jordanian undergraduate nursing students' perceptions of effective clinical teachers. Nurse Educ Today. 1999; 19(8):639-48,

8. Wong J, Wong S. Towards effective Clinical teaching in nursing. J adv Nurse.1987:12(4):505-13.

9. Benor DE, Leviyof I. The The development of students' perceptions of effective teaching: the ideal, best and poorest clinical teacher in nursing J Nurse Educ.1997;36(5):206-11.

10. Hosseiny N, Karimi Z, Malek zadeh J. The Situation of Clinical Education Based on Nursing Students' Opinion in Yasuj Nursing and Midwifery School. Iranian Journal of Medical education. 2005:5(2)171-5(Persian).

11. Haghani F, Jafari Mianaei S, Ehsani M. Reflective Learning and Teaching: A Review. Iranian Journal of Medical Education. 2014;13(11):989-98.

12. Arksey H, and O Malley L. (2005). Scoping Studies: Towards a Methodological Framework. International Journal of Social Research Methodology, 8(1), 19-32

13. Mays S, Arksey H, O'Malley L. Scoping Studies: towards a methodological framework. International J Social Res Methodol: Theory \& Pratice 2005; 8: 5.

14. Colquhoun HL, Levac D, O'Brien KK, Straus S, Tricco AC, Perrier L, et al. Scoping reviews: Time for clarity in definition, methods, and reporting. J Clin Epidemiol 2014; 67(12): 1291-4

15. Moradi M, Miralmasi A. Pragmatic research method (quantitative and qualitative research), first). Tehran: Iranian Academy of Statistical Analysis (School of Quantitative and Qualitative Research). Retrieved from www. analysisacademy.com. 2020

16. Gibbs G. Learning by doing: a guide to teaching and learning methods, Oxford, Further Education Unit, Oxford Polytechnic,1988.

17. Questions taken from: Jasper, M. Beginning reflective practice, Cheltenham, Nelson Thornes, 2003.

18. Smyth J. Developing and sustaining critical reflection in teacher education, Journal of teacher education, 40(2), pp 2-9, 1989

19. Mezirow J. Learning as transformation: Critical perspectives on a theory in progress. San Francisco: Jossey-Bass, 2000.

20. Borton T. (1970) Reach Touch and Teach, London: Hutchinson cited in Jasper M, 2003. Beginning Reflective Practice, heltenham: Nelson Thornes.:link download: Borton, T, 1970. Reach Touch and Teach, https://archive.org/ details/reachtouchteachs0000bort, 2003.

21. Borton (2014). Reach touch and teach. Nurse Education Today 34, 488-489, 2014.

22. Zarezadeh Y, Pearson P, and Dickinson, C. A model for using reflection to enhance inter professional education, International Journal of Education, 1(1) available from www.macrothink.org/ije, 2009.

23. Johns C. Becoming a reflective practitioner, 3rd ed. Oxford: Wiley Blackwell, 2009.

24. Palmer A, Burns S, and Bulman C. reflective practice in nursing.-Oxford: Blackwell Scientific Publications, 1994

25. Cottrell S. Skills for Success: the personal development planning handbook 2nd Ed, 2010

26. Basingstoke: Palgrave McMillan cited in Cottrell, S Critical Thinking Skills: developing effective analysis and argument 2nd Ed Basingstoke: Palgrave McMillan, 2011

27. Platzer H, Blake D, Ashford D. Barriers to learning from reflection: a study of the use of groupwork with post-registration nurses. Journal of advanced nursing. 2000;31(5):1001-8.

28. Ruth-Sahd LA. Reflective practice: A critical analysis of data-based studies and implications for nursing education. Journal of Nursing Education. 2003;42(11):488-97

29. Richardson JT. Methodological issues in questionnaire-based research on student learning in higher education. Educational psychology review. 2004;16(4):347-58.

30. Gustafsson C, Asp M, Fagerberg I. Reflective practice in nursing care: Embedded assumptions in qualitative studies. International Journal of Nursing Practice. 2007;13(3):151-60.

31. Chong MC. Is reflective practice a useful task for student nurses? Asian Nursing Research. 2009;3(3):111-20. 
32. Mettiäinen S, Vähämaa K. Does reflective web-based discussion strengthen nursing students' learning experiences during clinical training? Nurse Education in Practice. 2013;13(5):344-9.

33. Naicker $\mathrm{K}$. The role of educators in facilitating reflective learning in students 2013.

34. Ryan M, Ryan M. Theorising a model for teaching and assessing reflective learning in higher education. Higher Education Research \& Development. 2013;32(2):244-57

35. Muncy JA. Blogging for reflection: The use of online journals to engage students in reflective learning. Marketing Education Review. 2014:24(2):101-14.

36. Gašević D, Mirriahi N, Dawson S, editors. Analytics of the effects of video use and instruction to support reflective learning. Proceedings of the fourth international conference on learning analytics and Knowledge; 2014: ACM.

37. Ugalde J. The relationship between reflective learning, interest and motivation and achievement toward reading standards in middle school. 2015.

38. Saperstein AK, Lilje T, Seibert D. A model for teaching reflective practice. Mil Med. 2015:180(4 Suppl):142-6.

39. Freshwater D (ed). Therapeutic nursing: Improving patient care through self awareness and reflection, London: Sage, 2002.

40. Stewart M, Brown JB, Donner A, McWhinney IR, Oates J, Weston WW, Jordan J. 2000. The impact of patient-centered care on outcomes. J Fam Pract 49(9):805-807.
41. Schon DA. The reflective practitioner. Temple Smith: London (1983)

42. Eraut M. Developing professional knowledge and competence. London: Falmer Press (1994)

43. Baernstein A, Fryer-Edwards K. 2003. Promoting reflection on professionalism: A comparison trial of educational interventions for medical students. Acad Med 78:742-747.

44. Sobral DT. 2000. An appraisal of medical students' reflection-in-learning. Med Educ 34:182-187.

45. Niemi PM. 1997. Medical students' professional identity: Self-reflection during the pre-clinical years. Med Educ 31:408-415.

46. Wiecha JM, Vanderschmidt H, Schilling K. 2002. HEAL: An instructional design model applied to an online clerkship in family medicine. Acad Med 77:925-926.

47. Lonka K, Slotte V, Halttunen M, Kurki T, Tiitinen A, Vaara L, Paavonen J. 2001 Portfolios as a learning tool in obstetrics and gynaecology undergraduate training. Med Educ 35:1125-1130.

48. Grant A, Kinnersley P, Metcalf E, Pill R, Houston H. 2006. Students' views of reflective learning techniques: An efficacy study at a UK medical school. Med Educ 40(4):379-388.

49. Sandars J, Homer M. Reflective learning and the net generation. Med Teach 30:877-879, 2008.

50. Gauntlett D. Creative explorations. Abingdon: Routledge, 2007.

This work is licensed under a Creative Commons Attribution-NonCommercial 3.0 Unported License which allows users to read, copy, distribute and make derivative works for non-commercial purposes from the material, as long as the author of the original work is cited properly. 